\title{
Lymphocyte counts in patients with ANCA-associated vasculitis
}

\author{
Andreas Holbro $\cdot$ Philipp Schuetz $\cdot$ Christoph Berger · \\ Christoph Hess · Thomas Daikeler
}

Received: 5 August 2008 / Accepted: 21 October 2008 / Published online: 8 November 2008

(C) Springer-Verlag 2008

\begin{abstract}
How lymphocyte counts relate to treatmentresponse in patients with ANCA-associated vasculitis (AAV) is controversial, and data on short-term variability of lymphocyte counts are lacking. Retrospective single center evaluation of disease activity and lymphocyte counts in patients with AAV, and of lymphocyte counts in kidney transplant-recipients, were done; both at the University Hospital Basel, Switzerland. Twenty-three patients with AAV were included. Remission was achieved in all patients. Ten patients experienced a relapse after a median of 66 weeks (range 15-189 weeks). Median lymphocyte counts at diagnosis were significantly higher than at remission $\left(1.38 \times 10^{9} / \mathrm{L}\right.$ vs. $\left.0.99 \times 10^{9} / \mathrm{L} ; P=0.007\right)$. By contrast, median lymphocyte counts at remission and relapse did not differ significantly. However, intra-individual variability of lymphocyte counts early after diagnosis was high [median lymphocyte variability-range during the first 3 weeks of treatment 1.57 (range $0.27-3.95$ ), $n=17$ ]. This variability was not specific to patients with AAV, but was
\end{abstract}

C. Hess and T. Daikeler are equal contributors.

A. Holbro

Division of Hematology, University Hospital Basel,

4031 Basel, Switzerland

P. Schuetz

Division of Endocrinology, Institute of Clinical Epidemiology,

University Hospital Basel, 4031 Basel, Switzerland

C. Berger · C. Hess

Department of Internal Medicine,

University Hospital Basel, 4031 Basel, Switzerland

T. Daikeler $(\bowtie)$

Department of Rheumatology,

University Hospital Basel, 4031 Basel, Switzerland

e-mail: tdaikeler@uhbs.ch also observed in patients after kidney transplantation [variability of 1.76 (range $0.74-3.95, n=31$ )]. The significantly higher median lymphocyte counts at diagnosis of AAV make lymphocyte counts a valuable surrogate for the treatment-efficiency in clinical studies. By contrast, on a patient-level, variability of lymphocyte counts impedes meaningful interpretation of individual measurements.

Keywords Vasculitis · ANCA · Lymphocytes · AAV . Prognostic $\cdot$ Variability

\section{Introduction}

Therapeutic options for severe AAV are limited, and therapy-mostly cyclophosphamide (CYC)-based—remains a balancing act between disease- and treatment-related morbidity and mortality $[1,2]$. Factors predicting treatmentresponse would hence be important.

Lymphocytes, both of the T- and B-cell lineage, are thought to be involved in the pathogenesis of AAV [3-6]. How circulating lymphocyte counts relate to disease activity, however, remains controversial. One study reported that treatment-induced lymphopenia $\left(\leq 0.5 \times 10^{9} / \mathrm{L}\right)$ is associated with a high likelihood to achieve sustained remission [3, 7]. By contrast, another group suggested that, analogous to patients with systemic lupus erythematodes, lymphopenia in AAV reflects disease activity, with lymphocyte counts actually increasing in patients achieving remission $[8,9]$. While the reason for these contradictory findings remain unclear, neither study has taken into account short-term variability of lymphocyte counts and how this might impact study results.

Here, we investigated how in AAV-patients (1) median lymphocyte counts relate to disease activity on a population 
level, and (2) assessed, in these same individuals, shortterm lymphocyte count variability.

\section{Patients and methods}

Study populations

After obtaining approval by the institutional review board, disease activity and lymphocyte counts in patients with AAV (diagnosed between 1/1992 and 12/2007), and lymphocyte counts in kidney transplant-recipients (transplanted within the living-donor program between 1/2004 and 12/ 2006) were retrospectively assessed in patients treated at the University Hospital Basel, Switzerland. Medical charts from all patients with a definite diagnosis of AAV were reviewed to obtain demographic, clinical and laboratory data.

\section{Diagnosis and follow-up of AAV}

AAV was diagnosed according to American College of Rheumatology (ACR) criteria [10], the Birmingham Vasculits Activity Score (BVAS) [11] was calculated initially and for every subsequent visit.
Laboratory measurements

Lymphocyte counts were determined via routine flowcytometry $\quad$ ADVIA $^{\circledR}$ Hematology system, Siemens), ANCA titers were measured using indirect immunofluorescence (INOVA ${ }^{\circledR}$, San Diego), and ANCA were specified [myeloperoxydase (MPO) vs. proteinase3 (PR3)], and quantified using enzyme linked immunosorbent systems (DLD Diagnostika ${ }^{\circledR}$, Hamburg).

\section{Outcome parameters}

Remission of AAV was defined as complete absence of clinical symptoms and a daily prednisone-dose $\leq 7.5 \mathrm{mg}$, according to published criteria [12]. Relapse was defined as de novo disease activity according to the BVAS [11].

\section{Statistical analysis}

Discrete variables are expressed as counts (percentage), continuous variables as medians and ranges. Frequency comparison was done by Chi-square test. Two-group comparison of normally distributed data was performed by paired or unpaired Student's $t$ test. For not normally distributed
Table 1 Patients with AAV: disease manifestation, treatment and response to treatment

\footnotetext{
Abbreviations: $W G$ Wegener granulomatosis, CSS ChurgStrauss syndrome, $A A V n c$ ANCA-associated vasculitis not otherwise classified. Manifestation: organ involvement at presentation, $K$ kidney, $P$ lung, $I$ Intestinal, $M$ sinus/mucous, $A$ arthritis, $S$ skin, $E$ eye, $N$ neurologic, BVAS Birmingham Vasculitis Activity Score, CYC cyclophosphamide, $M T X$ methotrexat, $P R E D$ prednisone alone, $A Z A$ azathioprin, TTR time-to-remission in weeks, $T S R$ time since remission, + indicating ongoing remission
}

\begin{tabular}{|c|c|c|c|c|c|c|c|}
\hline Sex & Diagnosis & $\begin{array}{l}\text { Age at } \\
\text { diagnosis } \\
\text { (years) }\end{array}$ & Manifestation & $\begin{array}{l}\text { Initial } \\
\text { BVAS }\end{array}$ & $\begin{array}{l}\text { Initial } \\
\text { therapy }\end{array}$ & $\begin{array}{l}\text { TTR } \\
\text { weeks }\end{array}$ & $\begin{array}{l}\text { TSR } \\
\text { weeks }\end{array}$ \\
\hline $\mathrm{m}$ & WG & 43 & $\mathrm{~K}, \mathrm{P}, \mathrm{I}, \mathrm{M}, \mathrm{A}, \mathrm{S}, \mathrm{E}$ & 35 & CYC & 32 & $16+$ \\
\hline $\mathrm{m}$ & WG & 63 & $\mathrm{~K}, \mathrm{~A}, \mathrm{E}$ & 14 & CYC & 16 & $2+$ \\
\hline $\mathrm{m}$ & WG & 68 & $\mathrm{~K}, \mathrm{M}$ & 13 & CYC & 31 & $343+$ \\
\hline $\mathrm{m}$ & WG & 66 & $\mathrm{~K}, \mathrm{P}, \mathrm{A}, \mathrm{S}, \mathrm{E}$ & 26 & $\mathrm{CYC}$ & 28 & $438+$ \\
\hline $\mathrm{m}$ & WG & 44 & $\mathrm{~K}, \mathrm{P}, \mathrm{M}, \mathrm{A}, \mathrm{S}, \mathrm{N}$ & 23 & CYC & 25 & 32 \\
\hline $\mathrm{m}$ & WG & 29 & $\mathrm{~K}, \mathrm{P}, \mathrm{M}$ & 10 & CYC & 34 & $223+$ \\
\hline $\mathrm{m}$ & WG & 55 & $\mathrm{~K}, \mathrm{P}, \mathrm{M}, \mathrm{A}, \mathrm{S}, \mathrm{N}$ & 13 & CYC & 58 & $110+$ \\
\hline$f$ & WG & 70 & $\mathrm{P}, \mathrm{A}, \mathrm{S}$ & 9 & PRED & 19 & $1+$ \\
\hline$f$ & WG & 65 & $\mathrm{~K}, \mathrm{M}, \mathrm{A}, \mathrm{N}$ & 22 & AZA & 17 & 189 \\
\hline$f$ & WG & 47 & $\mathrm{~K}, \mathrm{P}, \mathrm{A}, \mathrm{S}$ & 14 & CYC & 24 & $254+$ \\
\hline$f$ & WG & 77 & $\mathrm{~K}, \mathrm{P}, \mathrm{M}, \mathrm{N}$ & 18 & CYC & 83 & 15 \\
\hline$f$ & WG & 33 & M & 6 & MTX & 10 & 93 \\
\hline$f$ & WG & 22 & $\mathrm{P}, \mathrm{M}, \mathrm{A}, \mathrm{S}$ & 12 & CYC & 87 & 38 \\
\hline$f$ & WG & 71 & $\mathrm{~K}, \mathrm{I}, \mathrm{M}$ & 28 & CYC & 13 & $122+$ \\
\hline$f$ & WG & 51 & $\mathrm{~K}, \mathrm{M}, \mathrm{A}$ & 21 & CYC & 42 & 167 \\
\hline$f$ & WG & 27 & $\mathrm{P}, \mathrm{M}, \mathrm{S}$ & 13 & MTX & 17 & $5+$ \\
\hline$f$ & WG & 60 & $\mathrm{M}, \mathrm{A}, \mathrm{S}, \mathrm{N}$ & 15 & MTX & 38 & 18 \\
\hline$f$ & WG & 60 & $\mathrm{M}, \mathrm{A}, \mathrm{E}$ & 9 & MTX & 19 & 168 \\
\hline $\mathrm{m}$ & CSS & 33 & $\mathrm{P}, \mathrm{M}, \mathrm{N}$ & 17 & CYC & 26 & 35 \\
\hline$f$ & CSS & 67 & $\mathrm{P}, \mathrm{M}, \mathrm{A}$ & 6 & CYC & 25 & 179 \\
\hline$f$ & CSS & 51 & $\mathrm{P}, \mathrm{S}, \mathrm{N}$ & 10 & CYC & 29 & $294+$ \\
\hline $\mathrm{m}$ & AAV nc & 58 & $\mathrm{~K}$ & 12 & CYC & 40 & $15+$ \\
\hline$f$ & AAV nc & 44 & $\mathrm{~K}, \mathrm{P}, \mathrm{A}$ & 12 & AZA & 13 & $66+$ \\
\hline
\end{tabular}




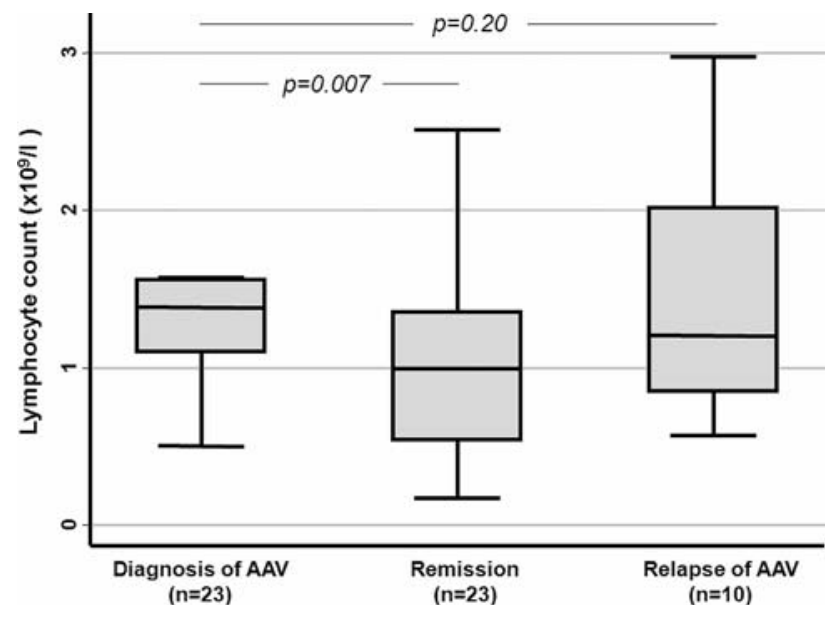

Fig. 1 Lymphocyte counts at diagnosis, in remission and at relapse of AAV. Boxes denote median and interquartile ranges; whiskers denote ranges

data, the Mann-Whitney $U$ test for unpaired data and the Wilcoxon's matched pair signed rank test for paired data were used. All testing was two-tailed, and $P$ values $<0.05$ were considered to indicate statistical significance. For all statistical analysis STATA 9.2 (Stata Corp ${ }^{\circledR}$, College Station, TX) was used.

\section{Results}

Patient's characteristics

Of the 33 AAV patients identified, 23 (70\%) were included in the analysis, 10 patients (30\%) had to be excluded from the analysis because of missing data, being lost during follow-up, or due to concurrent diagnoses other than AAV necessitating immunosuppressive therapy. Wegener's granulomatosis was diagnosed in 18/23 patients (78\%), ChurgStrauss Syndrome in $3 / 23$ patients (13\%), two patients had AAV not otherwise classified. A total of $14 / 23$ patients were female $(61 \%)$, the median age at diagnosis was 55 years (range, 22-77 years). Relevant baseline characteristics of the AAV study population are summarized in Table 1. Median BVAS at diagnosis was 13 (range 6-35). Sixteen out of twenty-three patients had CYC as part of their induction therapy. Median CYC dose-to-remission was $13.5 \mathrm{~g}$ (range, $1.5-76.5 \mathrm{~g}$ ). All 23 patients (100\%) achieved remission [median time-to-remission, 26 weeks (range 10-87 weeks)], $10 / 23$ patients $(43 \%)$ experienced a relapse [median timeto-relapse: 66 weeks (range 15-189)]. The control-cohort of kidney transplant-recipients $(n=31)$, transplanted consecutively between 2004 and 2006) received immunosuppressive regimens containing glucocorticoids, mycophenolate mofetil, and tacrolimus. Ten/31 (33\%) transplant-recipients were female; the median age at transplantation was 50 years (range, 19-68 years).

\section{Lymphocyte counts}

Lymphocyte counts were analyzed (1) cross-sectional (i.e., on a population level) at diagnosis and in remission, and (2) longitudinally (i.e., intra-individually) during the first 3 weeks after diagnosis. On a population level, median lymphocyte counts at diagnosis [first measurement $1.38 \times 10^{9} \mathrm{~L}$ (range: $0.5-3.11$ )] were significantly higher than median lymphocyte counts in remission [first measurement in remission, $0.99 \times 10^{9} \mathrm{~L}$ (range, 0.17-3.1), $P=0.007]$ (Fig. 1). Relapsing and non-relapsing patients had similar lymphocyte counts both at diagnosis and in remission [median lymphocyte counts at diagnosis, relapsing patients: 1.54 (range $0.77-3.11$ ), non-relapsing patients: 1.34 (range $0.5-2.56$ ),$P=0.15$, median lymphocyte counts in remission, relapsing patients: 0.94 (range $0.17-3.1$ ), nonrelapsing patients: 0.99 (range $0.41-2.82$ ),$P=0.88$ ]. Timeto-remission was independent of initial lymphocyte counts $(P=0.8$, Cox regression).

However, serial lymphocyte counts early after diagnosis [defined here as $\geq 4$ (range 4-17) measurements during the first 3 weeks after diagnosis; available in $n=17$ AAVpatients] revealed a high intra-individual variability of lymphocyte counts, even if measured in very short (daily) intervals [median intra-individual variability-range; 1.57
Fig. 2 Variability of serial lymphocyte counts during the first 3 weeks of therapy in patients with AAV (left panel) and in patients after kidney transplantation (right panel). Boxes denote median and interquartile ranges; whiskers denote ranges

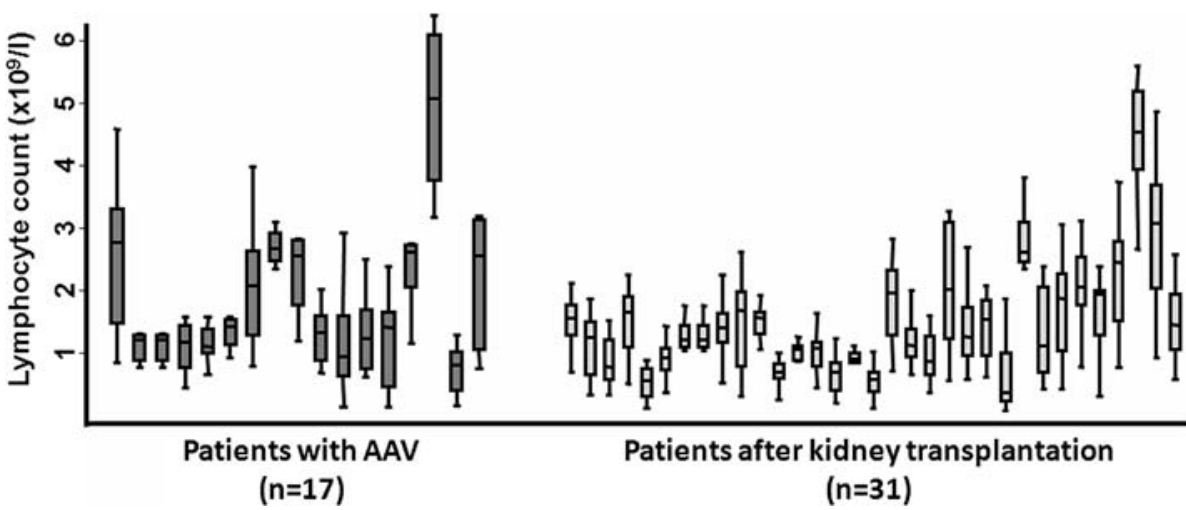


(range 0.27-3.599)]. The lymphocyte count variability in patients with AAV was compared to the variability in a cohort of kidney transplant-recipients during the first 3 weeks after transplantation ( $n=31,4-21$ measurements). The median lymphocyte count at transplantation was $0.95 \times 10^{9} / \mathrm{L}$ (range, $0.12-2.8$ ), the median intra-individual variability-range 1.76 (range 0.74-3.95). Variability of lymphocyte counts in AAV-patients and transplant-recipients was similar, excluding an AAV-specific phenomenon $(P=0.48)$ (Fig. 2).

\section{Discussion}

The key observations of this study are that (1) in patients with AAV median lymphocyte counts on a cohort level are higher at presentation than in remission, and (2) in a given AAV-patient intra-individual short-term variability of lymphocytes is making their value as an indicator of treatmentefficiency questionable. The major limitations of our study are its retrospective design, and the small number of patients that were studied. Despite these limitations, the range of the observed short-term lymphocyte count variability-which is essentially unaffected by the study design-may have implications possibly extending beyond the field of clinical AAV-research.

In the context of AAV, our data-on a cohort level-are in-line with the plausible notion stemming from a relatively large study stating that lymphocyte counts inversely associate with sustained remission [7]. However, by combining cohort-derived data and analyses in individual patients, our results indicate that the value of individual lymphocyte counts in reflecting treatment-efficiency is limited.

While for now remaining a provocative hypothesis, short-term (day-by-day!) variability of lymphocyte counts may also influence clinical decision making when judging immuno-competence, e.g., in patients infected with HIV or in transplant-recipients.

In summary, our study establishes a surprising shortterm variability of lymphocyte counts both in patients with $\mathrm{AAV}$, and in a heterogeneous group of kidney transplantrecipients. Larger, ideally prospective studies integrating short-term variability of peripheral lymphocyte counts and disease activity are needed to more definitely establish the value of lymphocyte counts as biomarkers for the treatment-efficiency in patients suffering from AAV.
Acknowledgments We thank Alan Tyndall, Jürg A Schifferli and Jürg Steiger for ongoing support.

\section{References}

1. Hoffman GS, Kerr GS, Leavitt RY, Hallahan CW, Lebovics RS, Travis WD et al (1992) Wegener granulomatosis: an analysis of 158 patients. Ann Intern Med 116(6):488-498

2. Talar-Williams C, Hijazi YM, Walther MM, Linehan WM, Hallahan CW, Lubensky I et al (1996) Cyclophosphamide-induced cystitis and bladder cancer in patients with Wegener granulomatosis. Ann Intern Med 124(5):477-484

3. Kallenberg CG (2007) Antineutrophil cytoplasmic autoantibodyassociated small-vessel vasculitis. Curr Opin Rheumatol 19(1):17-24. doi:10.1097/BOR.0b013e3280119842

4. Brouwer E, Stegeman CA, Huitema MG, Limburg PC, Kallenberg CG (1994) T cell reactivity to proteinase 3 and myeloperoxidase in patients with Wegener's granulomatosis (WG). Clin Exp Immunol 98(3):448-453

5. Bosch X, Guilabert A, Font J (2006) Antineutrophil cytoplasmic antibodies. Lancet 368(9533):404-418. doi:10.1016/S01406736(06)69114-9

6. Flossmann O, Jones RB, Jayne DR, Luqmani RA (2006) Should rituximab be used to treat antineutrophil cytoplasmic antibody associated vasculitis? Ann Rheum Dis 65(7):841-844. doi: $10.1136 /$ ard 2005.048900

7. Villa-Forte A, Clark TM, Gomes M, Carey J, Mascha E, Karafa MT et al (2007) Substitution of methotrexate for cyclophosphamide in Wegener granulomatosis: a 12-year single-practice experience. Medicine (Baltimore) 86(5):269-277

8. Izzedine H, Cacoub P, Launay-Vacher V, Bagnis C, Deray G (2002) Lymphopenia in Wegener's granulomatosis. A new clinical activity index? Nephron 92(2):466-471. doi:10.1159/ 000063303

9. Vila LM, Alarcon GS, McGwin G Jr, Bastian HM, Fessler BJ, Reveille JD (2006) Systemic lupus erythematosus in a multiethnic US cohort, XXXVII: association of lymphopenia with clinical manifestations, serologic abnormalities, disease activity, and damage accrual. Arthritis Rheum 55(5):799-806. doi:10.1002/art. 22224

10. Hunder GG, Arend WP, Bloch DA, Calabrese LH, Fauci AS, Fries JF et al (1990) The American College of Rheumatology 1990 criteria for the classification of vasculitis. Introduction. Arthritis Rheum 33(8):1065-1067

11. Luqmani RA, Bacon PA, Moots RJ, Janssen BA, Pall A, Emery P et al (1994) Birmingham Vasculitis Activity Score (BVAS) in systemic necrotizing vasculitis. QJM 87(11):671-678

12. Hellmich B, Flossmann O, Gross WL, Bacon P, Cohen-Tervaert JW, Guillevin L et al (2007) EULAR recommendations for conducting clinical studies and/or clinical trials in systemic vasculitis: focus on anti-neutrophil cytoplasm antibody-associated vasculitis. Ann Rheum Dis 66(5):605-617. doi:10.1136/ard.2006.062711 